\title{
Analysis of the Combination of Information Technology and Government Functions-CTake China MOOC as an Example
}

\author{
Binhua Qi \\ Wuhan University of Science and Technology, Hubei, China \\ E-mail:313918503@qq.com
}

\begin{abstract}
With the advent of "Internet +", the information age has followed, and the traditional teaching model is no longer fully qualified for the current and future teaching channels. The MOOC platform should be produced by the times. MOOC has set off a wave of education reform, and it will inevitably lead to the government's management transformation in the field of education. The government's management functions affect the development of MOOC This paper provides a reference for improving information technology by reviewing China's MOOC and current status issues, and guiding domestic MOOC information technology and government management.
\end{abstract}

Keywords: MOOC; Government; Information Technology.

\section{Introduction}

The development of information technology has broken down the fortress of time, space and region. More and more advanced technologies provide convenience for human society, such as medical treatment, education, modern government management and so on. For the application and perfection of new technology, it is usually found in the process of use that can make up for or omit problems, thus leading to the continuous innovation and development of information technology. Taking China MOOC as an example and referring to the research on MOOC by (CNKI) in recent years, this paper summarizes the current situation and problems of MOOC development in China. From the angle of the combination of government management and information technology, it puts forward the construction for the continuous improvement and development of information technology. Discussion.

\section{Background}

Massive Open Online Course (MOOC) is a large-scale open online course, which is a new product of the rapid development of computer technology and network communication technology in the information age. In 2008, the director of Network Communication and Innovation at Prince Edward Island University in Canada and the Senior Research Fellow of the National Institute of Humanities Education Technology Application jointly proposed the term MOOC. In 2011, it rapidly emerged in the United States ${ }^{1}$, starting in 2012 and causing it worldwide. New trends. As of the end of 2017, according to the latest statistics from ClassCentral, the total number of MOOC students has reached 78 million, and the number of new MOOC students in 2017 is 20 million. More than 800 universities participated in the MOOC new wave and launched from the end of 2016. The number of 6,850 courses has risen to 9,400. In terms of number of registered persons, the top five MOOC platforms are Coursera, edX, School Online, FutureLearn and Udacity (Shah, 2018a). China's largest MOOC platform school ranks third in the world, with the number of users. 9.3 million, it is also the only MOOC learning platform with non-English as the main language among the five platforms ${ }^{1}$.

In 2013, MOOC officially entered China. In May, Tsinghua University joined the American education platform Edx, and in October the first Chinese version of the MOOC platform was launched in the country, namely "School Online", in 2014 by Netease and Higher Education Press. Together, we launched a large-scale open online education platform for Chinese universities, MOOC. At the same time, there are other online education platforms of different scales, such as the University Online and the MOOC Academy. The Chinese MOOC has begun to develop rapidly. By the end of 2017, the number of colleges and universities collaborating on the MOOC platform of Chinese universities has reached 151 , and more than 1,000 courses have been offered, including 322 of the first batch of national online open courses $^{3}$. 


\section{MOOC platform}

3.1 MOOC learning system is a new product designed with the rapid development of computer technology and network communication technology, combining image, text, voice, communication and other information technology. It utilizes the development trend of network and video, and integrates dynamic video images and static images. Provides users with on-demand, real-time online learning systems in a way that integrates information such as change, sound, and text.

3.2 The MOOC platform considers all aspects of system compatibility, scalability and ease of maintenance, and adopts the $\mathrm{B} / \mathrm{S}$ architecture information service system. The entire software only needs to be installed on the server to provide services. Any user on the network who has access to the service system can access the information through a web browser.

3.3 When developing the system, select the appropriate development environment. Table 1 is the MOOC platform system development environment ${ }^{4}$ :

Table 1. MOOC platform system development environment.

\begin{tabular}{|c|c|}
\hline Name & Describe \\
\hline Application platform & J2EE \\
\hline Exploitation environment & JDK10.0 \\
\hline WEB server & Tomcat7.0 \\
\hline Programming language & $\begin{array}{c}\text { Java, Servlet, Maker, } \\
\text { javascript, Ajax, } \\
\text { Htm15 }\end{array}$ \\
\hline Development tools & $\begin{array}{c}\text { Eclipse, Flex, Red5 } \\
\text { video server }\end{array}$ \\
\hline Database management system & Sql server 2012 \\
\hline Server operating system & Windows 7 Ultimate \\
\hline
\end{tabular}

3.4 In the system structure, the MOOC management platform is responsible for managing students, teachers and administrators respectively. Student users can choose courses to study, discuss with each other, test and assignments, and final exams. Teacher users can conduct courses, assignments, interactive answering questions, and exam management. Administrator users can manage users as well as notifications.

MOOC learning systems follow the technical principles of stability, scalability, security, standardization and openness, maturity, advancement, reliability, maintainability, manageability, and ease of use. Standardization and openness are embodied in protocols and technologies that use international or industrial standards in a system that can be easily interconnected with other systems that adopt international standards, The vertical and horizontal interfaces of the system and other systems adopt international or industrial standards.

\section{China's MOOC development status and problems}

\subsection{Current phenomenon}

\subsubsection{Teaching quality is difficult to guarantee}

There are thousands or even tens of thousands of students in a course during the MOOC teaching period. The teacher can not guarantee that every student can grasp the new knowledge completely. Because the number of students is too large and the basic knowledge of each student is different, the teacher can not get the information of classroom effect in time, thus adjusting the teaching method or progress, which leads to the teacher often in the passive teaching period. At the end of an online exam, it is difficult to verify whether you tested or found cheating in the course of the exam.

\subsubsection{Credit certification is not uniform}

In the field of education, the credit certification of the MOOC platform course study is very confusing, there is no official requirement or the standard of the public approval, which is also explained to some extent, and the technical aspects of the online education learning system are not perfect. So far, there are three ways of the domestic online course credit recognition: the first is that some colleges and universities only carry out credit recognition on the self-built course of the school, that is, the self-built course of the school is set up on one or more of the designated platforms, and credits are awarded to the students who pass the course examination; The second is in addition to the self-built on-line open course and only for students in the school, while in policy orientation Under the joint drive of teaching reform, some colleges and universities organize their students to carry on the on-line high-quality online open courses to assist the teachers in their school to leave the line, answer questions and examine, and cooperate to complete the credit recognition of the online open courses. The third is the mutual recognition of credit between colleges and universities, which is set up by colleges and universities with similar teaching level. Through the construction of online teaching platform, they can work out the cooperative relationship and share high-quality online curriculum resources with each other. Students in the League can pass online exams and be recognized for credit ${ }^{5}$. Other ordinary students finish their courses on the MOOC platform and get them after the exam. The fact that the MOOC's academic credentials are not recognized by domestic authorities, universities, or the community reflects in another way the technical imperfections of the online education system. Information technology is not yet able to give network teaching is recognized as a guarantee.

\subsubsection{Students are not enthusiastic in their studies.}

At present, there is no environment and atmosphere of traditional education in the learning of MOOC platform. Instead of sitting in the classroom with the teacher face to face, students learn through the network at the other end of the information equipment. Most students are 
registered members who log into their accounts during class hours, and discussions about the course are rarely attended. Students choose to dive or hang up or exit the class during class interactions. Very few students can insist on completing a full course. Others give their accounts to others and ask them to replace them until the end of the course.

\subsection{Current problems}

\subsubsection{Teaching copyright issues increase student burden}

In the open online education platform, the opening of resources is bound to involve copyright issues in online teaching. In the course of online teaching, course content and third-party teaching aids must be authorized and recognized, while course materials with copyright licenses are limited, and copyright issues lead to an increase in personal burden. The MOOC platform provides convenient teaching and learning for teachers and students. However, if you truly master and understand the knowledge points in the course, you need other supplementary materials or electronic journals. Purchasing related resources will inevitably increase the burden on students.

\subsubsection{The quality of teaching and the limitations of student identification}

The faculty, student status, research level and project funds of ordinary higher vocational colleges and top universities are very different, which leads to the competition level of ordinary higher vocational colleges on MOOC is far lower than that of domestic first-class universities, thus reducing The public's recognition of the MOOC; the students learn courses, study and exams through the Internet, there is no complete and reliable identity verification for the whole link, resulting in various illusions.

\subsubsection{MOOC online course quality level is not uniform}

Many domestic MOOC courses are still in a state of nonupdate for a long time. The teaching ideas and methods of teachers are still in the traditional education mode, which leads students to feel bored and lose their enthusiasm for learning during the MOOC class. In addition, for the more logical science, physics, mathematics, metallurgy and other science and engineering courses, suitable for networked teaching, it is also suitable to use information technology assessment, network test and other methods to assess the quality of teaching, but for some literary subjects for example, university language, philosophy, etc, need to use multidimensional perspectives ${ }^{6}$.

\section{Make recommendations based on a combination of government}

\section{management technology}

and

information

In January 2017, the State Council issued the "13th FiveYear Plan for National Education Development" and proposed to "actively develop 'Internet +' Education" to promote the deep integration of information technology and education ${ }^{7}$. At present, MOOC is a new type of product that combines Internet information technology and education. The emergence of new things will inevitably lead to many problems and controversies. Through the above review of MOOC phenomena and problems, the following suggestions are made:

\subsection{Combining government functions with informatio $n$ technology to optimize resources}

To ensure the fairness of higher education is not only the basic requirement of the service government, but also the most fundamental value standard of the development of higher education ${ }^{8}$. The government should increase its investment in ordinary higher vocational colleges, reduce the cost of teaching resources in MOOC platform by means of financial subsidy, optimize information technology, and make information technology strengthen copyright protection of network teaching resources in a low cost operation mode at the same time. It also reduces the cost of acquiring knowledge for students; To improve the quality of teachers, to encourage the cooperation between the developed and the underdeveloped regions, between the high and low level institutions, to share high quality resources with each other, and to strengthen the cooperation between the general colleges and universities With the support of information technology and the combination of modern information technology and educational idea, the online education platform can minimize the differences of teachers' level, thus steadily promote the new education model in the information age.

\subsection{The credit certification system shall be establish ed and improved}

According to the development of MOOC in China, according to the actual situation of colleges and universities in various regions, according to the nature and difference of subject, the teaching quality is divided, and the relevant credit certification basis is worked out to break down the barrier of university alliance. Guide the community to MOOC recognition. At the same time, we also need to use information technology to obtain and deal with, constantly improve the judgment of credit recognition, in the course of learning, increase the time period of personal information verification, According to the completion rate of the course assignment, this paper counts whether the required amount of work in this course is up to the standard, and increases the data collection and processing of the activity and participation of the class discussion, in order to improve the MOOC platform provides reference for teaching quality, perfect intelligent detection of information technology, and prevent the phenomenon of double examination and 
cheating. Use advanced information technology means, government-led way, enhance the gold content of MOOC credit certification.

\subsection{The government should combine modern inform ation technology, standardize MOOC industry}

As a new education model, MOOC impacts on traditional education and challenges traditional education. MOOC connects learning education resources through the network, so that more and more people can combine their own environment. Conditions and other factors for selective learning. At present, China's MOOC does not have a complete curriculum construction standard, which leads to some courses in the MOOC platform broken, and the phenomenon of making up the number often occurs. The government should draw lessons from foreign advanced ideas and practices, monitor the MOOC industry with advanced information technology, strengthen the construction of information management, and formulate a special MOOC education system that conforms to the national conditions of our country. Department.

\subsection{The government should strengthen and guide the innovation of information technology}

The source of students on MOOC platform is more complex, which is mainly composed of party and government personnel, enterprises and institutions and students. There are obvious differences in the basic knowledge level among the students. This requires information technology to identify the level of students' knowledge, to push quality teaching courses for different students, and to simulate the classroom atmosphere with advanced information technology, such as image processing and information transmission, in the teaching process. Experiment class, outdoor teaching and so on, develop a variety of teaching methods, enhance students' hands-on ability, practical ability and enthusiasm for learning. Use policies to promote the development of information technology improve our teaching level and quality.

\section{Conclusion}

With the advent of the information age, modern information technology has spread to all kinds of industries. The traditional education mode is no longer the only way of education. The modern education concept is to combine advanced technology with education. Train the compound type talented person that accords with the science and technology age. With the emergence of modern new government, advanced information technology is not only the master and application of scientific research personnel, but also the use of government in the management function. Advanced information technology provides technical support for the transformation of modern government functions. Information technology should make full use of the innovation in many fields such as image processing, data collection and retrieval, information transmission and so on, and change the traditional operation mode, which is convenient and quick. In modern society.

\section{References}

1. Chris Parr. MOOC Creators Criticize Courses' Lack of Creativity $[\mathrm{J}]$. Times Higher Education, 2015(6):58.

2. Yu Wang, Shufang Luo, Yizhou Fan, Qiong Wang. Review of the Development of Global Mutu Lessons in 2017 [J]. Distance Education in China, 2018, (09): $53-61+80$.

3. Office of the Ministry of Education. Notice of the General Office of the Ministry of Education on the Announcement of the Results of the 2017 National Online Open Courses [EB/OL]. (2017-12-26)[201801-12]. $\quad \mathrm{http} / / \mathrm{www} \cdot \mathrm{moe} . e d u . c n / \mathrm{src}-$ site/A08/s5664/moe 1623/s3843201801/t20180112 324478.html.

4. Dafei Wu. Design and Development of MOOC Management platform [J]. Computer knowledge and Technology, 201814 (27): 47-49 52.

5. Jide Wang, Bo Li. Online Open Course Credits Recognition: Forms, Problems and Suggestions [J]. Open Education Research, 2018, 24 (05): 39-45.

6. Yongli Zhang, Haiyan Qiang. The current university reform in the era of "Mu Class" $[\mathrm{J}]$. Economic and Trade Practice, 2018, (08): 315-316.

7. State Council. Notice of the State Council on Printing and Distributing the 13th Five-Year Plan for the Development of National Education [EB/OL]. http:/www.gov.cn/zhengce/content/201701/19/content 5161341.htm, 2018-07-28.

8. Ping Zhu, Dongping Sun. On the Function Positioning and Service Value of the Government in the Reform of Higher Education Management System [J]. Heilongjiang Higher Education Research, 2017, (04): 67-70. 